\title{
PERANAN PATROLI SATUAN SABHARA DALAM UPAYA PENGOPERASIAN TINDAK KEJAHATAN DI WILAYAH HUKUM POLDA BALI
}

\author{
I Nyoman Loka Hari Prabawa, Anak Agung Sagung Laksmi Dewi, Luh Putu Suryani \\ Fakultas Hukum Universitas Warmadewa, Denpasar-Bali, Indonesia \\ laksmidewi@gmail.com, suryaniputu@gmail.com
}

\begin{abstract}
Abstrak
Pelaksanaan operasi rutin kepolisian mempan menggegas kejahatan dan menciptakan keselarasan ketaatan umum. Penelitian ini bertujuan menjelaskan kapabilitasan patroli Satuan Sabhara dalam upaya pengoperasian tindak kejahatan di wilayah hukum Polda Bali dan menjelaskan faktor-faktor apakah yang menghambat patroli Satuan Sabhara dalam upaya pengoperasian tindak kejahatan di wilayah hukum Polda Bali. Tipe penelitian yang digunakan adalah penelitian hukum empiris. Pendekatan yang digunakan adalah pendekatan peraturan Perundang-Undangan. Sumber data adalah sumber data hukum primer dan sekunder. Tehnik pengumpulan data dilakukan dengan wawancara kaidah dan dokumentasi. Setelah bahan hukum terkumpul, kemudian diolah dan di analisis dengan analisis sekaidah kualitatif. Hasil penelitian menunjukkan bahwa Kapabilitasan patroli Satuan Sabhara dalam upaya pengoperasian tindak kejahatan di wilayah hukum Polda Bali adalah menangkap dan melaporkan eksekutor kejahatan yang tertangkap tangan pada saat patroli, mengamankan korban, eksekutor, saksi, barang bukti dan Tempat Kejadian Perkara selanjutnya faktor-faktor yang menghambat patroli Satuan Sabhara dalam upaya pengoperasian tindak kejahatan di wilayah hukum Polda Bali yaitu faktor internal yakni kurangnya personel polisi, informasi, tidak diketemukan barang bukti dan kurangnya sarana prasarana, sedangkan faktor eksternal yaitu kurangnya kesadaran masyarakat, korban tidak segera melapor dan adanya rasa takut kepada Polisi.
\end{abstract}

Kata Kunci : Kapabilitasan, Patroli Satuan Sabhara, Pengoperasian Kejahatan

\begin{abstract}
The carrying out of routine police operations is capable of preventing crime and harmonizing public obedience. This study aims to explain the patrol capabilities of the Sabhara Unit in an effort to operate criminal acts in the jurisdiction of the Bali Regional Police and explain what factors are hindering the Sabhara Unit patrols in the effort to operate criminal acts within the jurisdiction of the Bali Regional Police. The type of research used is empirical legal research. The approach used is the Legislative Regulations approach. Data sources are primary and secondary legal data sources. Data collection techniques were carried out by interviewing rules and documentation. After the legal materials are collected, they are processed and analyzed using qualitative method analysis. The results showed that the Sabhara Unit patrol capability in an effort to operate a crime in the jurisdiction of the Bali Regional Police was to arrest and report the criminal executor who was caught redhanded while patrolling, securing the victim, executor, witnesses, evidence, and the location of the next case the factors that hinder patrols of the Sabhara Unit in an effort to operate criminal acts in the jurisdiction of the Bali Regional Police, namely internal factors, namely lack police personnel, information, no evidence found and lack of infrastructure, while external factors are lack of public awareness, victims do not immediately report and fear the Police.
\end{abstract}

Keywords: Capability, Sabhara Unit Patrol, Operation Crime

\section{PENDAhuluan}

Masalah global yang terjadi, tidak terkecuali di Indonesia, tentang kejahatan. Semua bangsa menghadapi masalah yang sama, tanpa terkecuali. Kejahatan Kriminalitas termasuk juga dapat membuat resah publik kemudian mengakibatkan rugi tergolong tinggi pada perorangan, publik dan pemerintah (Makhrus Munajat, 2009). Salah satu Tupoksi Kepolisian yang berpengaruh dan mempan terhadap timbulnya kejahatan pada pngoperasian dan pngungkapan sebuah peristiwa melanggar hukum adalah tugas preventif, dikarenakan luasnya cakupan kemudian perumusan kata-kata yang bisa melakukan apapun apabila dapat memelihara keamanan dan tanpa melanggar hukum. Ada empat tindakan pokok preventif yaitu mengatur, menjaga, mengawal dan patroli. Semakin banyaknya 
tuntutan dan kebutuhan akan menjadi awal terciptanya suatu tindakan yang dapat mengundang niat jahat orang tersebut, mualai dari pencurian ataupun perbuatan melanggar hukum lainnya. Polisi satuan sabhara memiliki kapabilitasan dalam menggegas dan menanggulangi kejahatan terutama di kota Gianyar.

Melakukan patroli di titik-titik yang dilalui banyak kendaraan yang dilakukan secara teratur dengan waktu 24 jam dengan bergilir dan dilakukan dengan serius dengan penuh dengan tanggung jawab sehingga kewajiban yang dilakukan pihak kepolisian juga bisa terlaksankan.Kepolisian Daerah Bali sebisanya menjalankkan kapabilitas-kapabilitasan dan kewajiban sebagai anggota Polri, dengan membuat program- program yang akan mampu memantau, mengawasi dan mencegah tindakan kejahatan. Salah satunya adalah melaksanakan bentuk Patroli Terpadu yang memiliki tujuan untuk menjaga keamanan dan keselarasan ketaatan masyarakat. Patroli merupakan sebuah tindakan yang dijalankan kepolisian yang dilaksanakan dua atau lebih anggota Polri dalam upaya menggegas bersemukanya situasi dan kondisi, dengan cara menyambangi, menjelajah, mngamati, mngawasi, meperhatikan sikon yang diasumsikan. Sebagai bukti pada antisipasi kelakuan jahat dibutuhkan ilmu mengenai tindakkan jahat teresebut timbul, situasi atau keadaan social yang berpengaruh karena lingkungan, kultur budaya yang artinya didalam pengoperasian serta untuk mengungkap sebuah tindakan kejahatan dibutuhkan pasukan yang mempunyai ilmu tersebut dan juga proses yang pas dalam pengoperasiannya (Ate, 2012).

Kegiatan pengoperasian harus dilakukan secara konsisten oleh polisi jadi prosesnya mencakup jam rawan, tempat rawan, serta kaidah menunaikan tindakan jahat yang efektif menggegas tindakan kejahatan dan membuat keselarasan ketaatan umum. Syarat absolut untuk meningkatkan kualitas dan kedamaian hidup masyarakat, pada target pertama ialah memberantas, setidaknya mengurangi bersemukanya timbulnya pengingkaran atau tindakan melanggar hukum (Bayler, 1998).

Ada beberapa penelitian terdahulu yang meneliti permasalahan yang relevan dengan penelitian ini yaitu H. Burhanuddin, (2017); (Djanieb, 2020); (Setiawan, 2014) mengungkapkan bahwa kegiatan patroli terpadu dilaksankan secara efektif, guna untuk menjaga keamanan masyarakat, namunada beberapa kendala yang dihadapi oleh kepolisian dilapangan saat melakukan kegiatan patroli yaitu sarana dan prasarana. Walaupun sudah banyak peneliti melakukan terkait masalah patroli ini, namun sampai saat masih terdapat kendala dalam melakukan pengoperasian tindak kejahatan. Oleh sebab itu penelitian ini dilakukan dengan tujuan untuk menjelaskan kapabilitasan patroli Satuan Sabhara dalam upaya pengoperasian tindak kejahatan di wilayah hukum Polda Bali dan faktor-faktor apakah yang menghambat patroli Satuan Sabhara dalam upaya pengoperasian tindak kejahatan di wilayah hukum Polda Bali

\section{METODE PENELITIAN}

Penelitian ini didesain dengan penelitian hukum empiris dengan penedekatan peraturan PerundangUndangan (Bambang, 2002). Adapun sumber data adalah data primer dan sekunder. Tehnik pengumpulan data dilakukan dengan wawancara dan do kumentasi. Setelah bahan hukum terkumpul, kemudian diolah dan di analisis. Untuk menganalisis bahan-bahan hukum yang telah terkumpulkan maka teknis analisis yang digunakan adalah dengan analisis kualitatif (Sugiyono, 2005).

\section{HASIL DAN PEMBAHASAN}

\section{Kapabilitasan patroli Satuan Sabhara dalam upaya pengoperasian tindak kejahatan di wilayah hukum Polda Bali}

Kepolisian Daerah Bali sebisanya menjalankkan kapabilitas-kapabilitasan dan kewajiban sebagai anggota Polri, dengan membuat program-program yang akan mampu memantau, mengawasi dan mencegah tindakan kejahatan. Salah satunya adalah melaksanakan bentuk Patroli Terpadu yang memiliki tujuan untuk menjaga keamanan dan keselarasan ketaatan masyarakat. Patroli merupakan sebuah tindakan yang dijalankan kepolisian yang dilaksanakan dua atau lebih anggota Polri dalam upaya menggegas bersemukanya situasi dan kondisi, dengan cara menyambangi, menjelajah, mngamati, mngawasi, meperhatikan sikon yang diasumsikan dapat menyebabkan berbagai ganjalan kamtibmas, dan dituntut keberadaan Polri agar menunaikan tindakan kepolisian guna mengampu keselarasan ketaatan dan menjamin keamanan umum masyarakat. Sebagai bukti pada antisipasi kelakuan jahat dibutuhkan ilmu mengenai tindakkan jahat teresebut timbul, situasi atau keadaan social yang berpengaruh karena lingkungan,kultur budaya yang artinya didalam pengoperasian serta 
untuk mengungkap sebuah tindakan kejahatan dibutuhkan pasukan yang mempunyai ilmu tersebut dan juga proses yang pas dalam pengoperasiannyaSamapta Bhayangkara (Sabhara) adalah salah satu pelaksana utama Kepolisian Daerah (Polda) yang membina Kesamaptaan Kepolisian yang meliputi tindakan-tindakan patroli antar wilayah, pengamanan unjuk rasa dan pengoperasian massa.

Kapabilitasan Sabhara merupakan sebagian kapabilitasan Kepolisian yang bersifat preventif yang memerlukan Polisi Satuan Sabhara memiliki kapabilitasan dalam menggegas dan menanggulangi kejahatan terutama di kota Gianyar. Melakukan patroli di titik-titik yang dilalui banyak kendaraan yang dilakukan secara teratur dengan waktu 24 jam dengan bergilir dan dilakukan dengan serius dan penuh tanggung jawab sehingga kewajiban yang dilakukan pihak kepolisian juga bisa terlaksankan.

Kepolisian Daerah Bali sebisanya menjalankkan kapabilitas-kapabilitasan dan kewajiban sebagai anggota Polri, dengan membuat program-program yang akan mampu memantau, mengawasi dan mencegah tindakan kejahatan. Salah satunya adalah melaksanakan bentuk Patroli Terpadu yang memiliki tujuan untuk menjaga keamanan dan keselarasan ketaatan masyarakat. Polisi Satuan Sabhara memiliki kapabilitasan dalam menggegas dan menghadapi tindakan kejahatan yang utama terjadi pada kota besar, kemudian diluar kapabilitasan-kapabilitasan. Patroli Satuan Sabhara tersebut dilakukan pada siang maupun aktifitaskekerasansimpatik. Polisi Satuan Sabhara memiliki kapabilitasan dalam menggegas dan menanggulangi kejahatan terutama di kota Gianyar. Melakukan patroli di titik-titik yang dilalui banyak kendaraan baik itu pagi, siang, sore dan malam hari sehingga kewajiban yang dilakukan pihak kepolisian juga bisa terlaksankan. Patroli Satuan Sabhara mempan sebagai tindakan antisipasi dan pengoperasian kejahatan. Berkaitan tupoksi umum Polri Satuan Sabhara yaitu mengampu keamanan dan keselarasan ketaatan (Abdillah, 2017).

\section{Faktor-Faktor yang Menghambat Patroli Satuan Sabhara dalam Upaya Pengoperasian Tindak Kejahatan di Wilayah Hukum Polda Bali}

Patroli Sabhara mempunya beberapa unit dengan tupoksi yang sudah diatur atau diabagi menjadi satuan-satuan, yang sudah direncanakan dengan pengaturan tanpa menyebabkan ketimpangan. Tetapi tetap semua unit mempunyai sasaran/tujuan yang sama yang dilakuakan dengan penuh tanggung jawab dan sigap dalam mencegah kejahatan tersebut. Berkaitan dengan tugas pokok kepolisian sebagai pengayom masyarakat, maka pihak kepolisian berkewajiban untuk menjaga kondisi kehidupan masyarakat agar tetap kondusif. Salah satunya dengan menekan angka kejahatan dalam hal adalah ini aksi-aksi kejahatan yang marak timbul di masyarakat.

Faktor internal penghambat dalam antisipasi tindak kejahatan di wilayah hukum Polda Bali antara lain :

1. Kurangnya personel polisi

Upaya pengoperasian terhadap timbulnya suatu tindak kejahatan memerlukan kapabilitas. Kurangnya personel di daerah yang rawan timbulnya aksi kejahatan menyebabkan eksekutor akan leluasa untuk menunaikan tindakan kriminal karena tidak adanya pihak aparat penegak hukum di tempat yang biasanya eksekutor menunaikan aksi kejahatannya. Maka dari pada itu jumlah personil perlu ditingkatkan lagi guna meningkatkan kualitas kerja para pihak kepolisian yang berimbas pada meningkatnya ketertiban dan keamanan masyarakat.

\section{Kurangnya informasi}

Pengoperasian dalam menindak sebuah kasus dperlukan sebuah informasi yang akurat serta cepat, dikarenakan dengan informasi yang akuarat kepolisian akan dengan cepat dapat menangani kasus tersebut. Polda bali juga selama ini kurang mendapat inforamsi yang akuratt dan cepat dikarenakan juga minimnya kerjasama masyarakat sebagai sumber informasi padahal segala bentu info yang berasal dari masyarakat sangat penting untuk dilaporkan guna membantu pihak kepolisian dalam memberantas suatu tindakan melanggar hukum yang selama ini mengganggu ketertiban dan ketentram masyarakat itu sendiri. Kendala penegakan hukum terhadap eksekutor tindak kejahatan karena kurangnya informasi yang diperoleh oleh kepolisian dari masyarakat/warga. Masyarakat cenerung males atau engan dan tidak mau repot, kemudian juga terkadadang warga enggak mau terlibat pada masalah yang terjadi yang dipengaruhi beberapa factor seperti takut akan terlibat, males ikut dengan masalah-masalah rumit dan lain sebagainya. 


\section{Tidak diketemukan barang bukti}

Proses yang dilakukan dalam menangkap seorang eksekutor kejahatan yang diduga menunaikan pelanggaran sangat diperlukan bukti yang digunakan untuk menjerat, yang seyogyanya sebagai dasar pihak kepolisian dalam memnangkap dan kemudian memproses ke tahap selanjutnya yang kemudian dapat dihukum sesuai perbuatannya, tanpa barang bukti kepolisian tidak akan dapat menangkap maupun memproses yang menyebabkan gagalnya penanggulangan tindakan kejahatan yang terjadi tersebut. Polda Bali adalah salah satu intstasi yang belum memperoleh kaidah tersebut.

\section{Kurangnya sarana dan prasarana}

Sarpras adalah salah satu lagi hambatan yang dialami oleh pihak kepolisian. Salah satunya yang sering dan sangat perlu sekali adalah kendaraan yang wajib dimiliki Polda Bali sehingga membuat sulit dalam menjalankan tindakan atau operasi. Cuma ada 2 motor dan 1 mobil yang benar benar dimiliki Polda Bali yang saya nilai sungguh sangat kurang dan perlu untuk ditambah. Tidak adanya mesin printer dan computer yang swadaya. Yang kemudian mengerucut kurangnya anggaran yang dibutukan pada era modern seperti sekarang ini.

Faktor eksternal penghambat petugas kepolisian dalam antisipasi tindak kejahatan antara lain:

1. Kurangnya kesadaran masyarakat

Kurangnya kesadaran masyarakat akan pentingnya keselamatan menyebabkan masyarakat menyerahkan tugas pengabdian masyarakat kepada polisi, Namun masyarakat juga harus memiliki kemampuan menjaga keamanan. Kapasitas masyarakat yang sangat besar dalam menangani kejahatan, dalam hal ini polisi memang perlu mendapatkan laporan dari masyarakat tentang perilaku atau orang-orang yang mencurigakan yang dapat menyebabkan atau melakukan tindak pidana. Banyak orang yang tidak bersedia untuk melaporkan atau memberikan informasi tentang kejahatan yang sedang berlangsung, baik yang sedang berlangsung maupun yang telah terjadi, dan lebih cenderung menghindari berurusan dengan polisi sebisa mungkin.Mereka merasa bahwa polisi hanya akan mengganggu aktivitas mereka, terutama ketika mereka harus pergi. Saat kantor polisi memberikan informasi. Masyarakat sebagai sumber informasi tentang tindak pidana, meski telah melakukan konsultasi hukum, tetap khawatir masyarakat akan curiga terhadap eksekutornya. Publik khawatir dengan risiko yang mungkin mereka hadapi jika melaporkan kejahatan yang mereka alami atau sadari.

Banyaknya hambatan dan tindakan terhadap kemampuan dan kemampuan polisi dalam menjalankan tugasnya, yang menyebabkan menurunnya kepercayaan masyarakat terhadap polisi. Hal-hal yang menyebabkan ketidak percayaan masyarakat terhadap polisi antara lain tugas-tugas yang dilakukan oleh polisi dianggap rahasia, sehingga kurang transparan dan seringkali eksklusif (isolasi atau jarak dari masyarakat, penggunaan diskresioner untuk menjalankan tugasnya). Berbagai kepentingan, polisi menjalankan tugas-tugas lain di Polres) Selain tugas kepolisian, sarana pendukung kepolisian hanya terbatas dan tidak profesional.

2. Korban tidak segera melapor

Korban tidak adanya keinginan mengambil tindakan segera, agar pelaku kejahatan segera diproses, informasi atau laporan tersebut harus diberikan oleh korban atau diketahui masyarakat.

3. Adanya rasa takut kepada Polisi

Informasi tentang tindak pidana dapat diperoleh dari hasil penyidikan pihak kepolisian maupun masyarakat Dalam hal ini sebagian kecil masyarakat di Denpasar masih takut terhadap polisi, sehingga pihak kepolisian akan terhambat dalam memperoleh informasi tentang tindak pidana remaja. Namun, bukan berarti polisi tidak bisa menyelesaikan masalah ini. Hanya saja polisi sendiri masih menghadapi banyak kendala dalam menangani perkara pidana. Oleh karena itu, secara fundamental seluruh tim belum terselesaikan dengan tepat seperti yang diharapkan oleh pihak kepolisian, dan persoalan kriminalitas yang belum terselesaikan menjadi tanggung jawab kepolisian, khususnya seluruh lapisan masyarakat.

\section{SIMPULAN DAN SARAN}

\section{Simpulan}

Berdasarkan uraian di atas, dapat simpulan bahwa Kapabilitasan patroli Satuan Sabhara dalam upaya pengoperasian tindak kejahatan di wilayah hukum Polda Bali adalah menangkap dan melaporkan 
eksekutor kejahatan yang tertangkap tangan pada saat patroli. Anggota patroli yang berdinas yang pertama kali melihat sekaidah langsung menemukan suatu kejadian segera mengamankan korban, eksekutor, saksi, barang bukti dan Tempat Kejadian Perkara (TKP) sampai Polisi yang berwenang menyambangi dan mengolah TKP guna proses hukum, selanjutnya faktor-faktor yang menghambat patroli Satuan Sabhara dalam upaya pengoperasian tindak kejahatan di wilayah hukum Polda Bali yaitu faktor internal yakni kurangnya personel polisi, kurangnya informasi, tidak ditemukan barang bukti dan kurangnya sarana dan prasarana dan faktor eksternal yaitu kurangnya kesadaran masyarakat, korban tidak segera melapor dan adanya rasa takut kepada Polisi.

\section{Saran}

Berdasarkan hasil penelitia, adapun saran yang diberikan oleh peneliti diharapkan kepada pihak kepolisian lebih profesional lagi dalam menjalankan tugasnya, menghilangkan jiwa-jiwa militer yang arogan dan menggantinya dengan sikap sebagai pelindung, pengayom dan pelayan masyarakat yang sesungguhnya. Pihak kepolisian juga merancang sistem yang jelas tentang patroli antisipasi tindakan kejahatan yang dapat menggegas tindak pidana kejahatan sekaidah komprehensif, selanjutnya diharapkan supaya ada penambahan anggota terutama pada Satuan Lalu Lintas dan Satuan Sabhara kemudian ditambahkannya sarana dan prasarana sehingga polisi dapat melaksanakan tugas patrolinya dengan mempan dan efisien, untuk mempermudah kegiatan patroli perlu ditingkatkan kerjasama antara instansi polisi, pemerintah dan masyarakat dengan tujuan menekan tingginya angka kejahatan khususnya di wilayah hukum Polda Bali.

\section{DAFTAR PUSTAKA}

Abdillah, R. (2017). Upaya Unit Patroli Satuan Sabhara dalam Mencegah Kasus Pencurian Kendaraan Bermotor di Wilayah Hukum Polres Cilacap. Advances in Police Science Research Journal, 1(3), 1031-1084.

Ate, R. (2012). Kapabilitasan Preventif Patroli BRIMOB dalam Pengoperasian Tindakan Kejahatan. Jurnal Ilmu Sosiatri, 1(1), 1-16.

Bambang, W. (2002). Penelitian Hukum dalam Praktek. Jakarta: Sinar Grafika.

Bayler, D. (1998). Police for The Future. Jakarta: Cipta Manunggal.

Djanieb, S. (2020). Kelayakan Ran Patroli R4 Fungsi Lantas dan Sabhara Dalam Memelihara Situasi Kamtibmas yang Kondusif. Jurnal Litbang Polri, 1(23), 74-84.

H. Burhanuddin, S. (2017). Efektifitas Pelaksanaan Patroli Terpadu dalam Upaya Menekan Tingkat Kriminalitas (pada Polres Bungo). Serambi Hukum, 11(1), 56-68.

Makhrus Munajat. (2009). Hukum Pidana Islam di Indonesia. Yogyakarta: Penerbit Teras.

Setiawan, I. P. (2014). Optimalisasi Peran Patroli Sabhara Polresta Pontianak Kota Berdasarkan Peraturan Kapolri Nomor 23 Tahun 2010 Terkait Peningkatan Daya Cegah dan Daya Tangkal Masyarakat Terhadapkejahatan. Jurnal Mahasiswa S2 Hukum UNTAN, 3(4).

Sugiyono. (2005). MemahamiPenelitian Kualitatif. Bandung: Alfabeta.

Undang-Undang Republik Indonesia Nomor 2 Tahun 2002 tentang Kepolisian

Republik Indonesia.

Peraturan Pemerintah Republik Indonesia Nomor 23 Tahun 2007 Tentang Daerah

Hukum Kepolisian Negara Republik Indonesia.

Peraturan Kapolri Nomor 1 Tahun 2009 Tentang Penggunaan Kekuatan Dalam

Tindakan Kepolisian 